\title{
Proposition of a simple binary grading of estimated blood loss during colon surgery
}

\author{
Hugo Teixeira Farinha ${ }^{1} \cdot$ David Martin ${ }^{1} \cdot$ Audrey Ramó ${ }^{1} \cdot$ Martin Hübner $^{1} \cdot$ Nicolas Demartines $^{1} \cdot$ Dieter Hahnloser $^{1}$
}

Accepted: 6 April 2021 / Published online: 16 April 2021

(C) The Author(s) 2021

\begin{abstract}
Purpose Intraoperative estimated blood loss (EBL) is often reported in nearly all surgical papers; however, there is no consensus regarding its measurement. The aim of this study was to determine whether EBL (ml) is as reliable and reproducible in predicting complications as a simple binary grading of EBL.

Methods All consecutive patients undergoing colectomies between January 2015 and December 2018 were included. EBL was assessed prospectively by the surgeon and anaesthesiologist in $\mathrm{ml}$ and with a binary scale: bleeding "as usual" versus "more than usual" by the surgeon. Differences between pre- and post-operative haemoglobin levels ( $\Delta \mathrm{Hb} \mathrm{g} / \mathrm{dl})$ were correlated to EBL. Blood loss impact on 30-day postoperative morbidity was analysed.

Results A total of 270 patients were included, with a mean age of 65 years (SD 17). Mean EBL documented by surgeons correlated to EBL by anaesthesiologists $(79.5 \mathrm{ml}$, SD 99 vs. $84.5 \mathrm{ml}$, SD $118, \varrho=0.926, p<0.001)$. Surgeons and anaesthesiologists' EBL correlated also with $\Delta \mathrm{Hb}(\varrho=-0.273, p=0.01$ and $\varrho=-0.344, p=0.01$, respectively). Patient with surgeon EBL $\geq 250 \mathrm{ml}$ or graded as "more than usual" bleeding had significantly more severe complications $(8 \%$ vs. $20 \%$, $p=0.02$ and $8 \%$ vs. $27 \%, p=0.001$, respectively).

Conclusion Anaesthesiologist and surgeon's EBL correlated with $\Delta \mathrm{Hb}$. Simple grading of blood loss as "usual" and "more than usual" predicted severe complications and higher mortality rates. This simple binary grading of blood loss in colon surgery could be an alternative to the estimation of blood loss in $\mathrm{ml}$ as it is easy to apply but needs to be validated externally.
\end{abstract}

Keywords Estimation $\cdot$ Blood loss $\cdot$ Colon surgery $\cdot$ Post-operative complications

\section{Introduction}

Estimated blood loss (EBL) is often reported on routine basis and is in many studies a risk factor for short- and long-term complications after colorectal surgery [1-7]. In a multicentre study including 1421 patients, EBL was associated with postoperative morbidity [1]. Two studies showed that EBL was an independent risk factor of prolonged postoperative ileus, however without clear cut-off in volume [2,3]. Several retrospective studies showed that $E B L \geq 250 \mathrm{ml}$ was associated with higher anastomotic leakage rate and 6-month mortality after

Hugo Teixeira Farinha and David Martin shared first

Dieter Hahnloser

dieter.hahnloser@chuv.ch

1 Department of Visceral Surgery, University Hospital Lausanne, CHUV, Rue du Bugnon 46, 1011 Lausanne, Switzerland colorectal surgery $[4,6]$. In emergency colorectal procedures, high EBL $(\geq 1000 \mathrm{ml}$ ) was associated with in-hospital mortality [5]. Furthermore, a review showed that intraoperative blood transfusions represented an independent risk factors for intra- and post-operative complications and adversely affected outcomes in colorectal surgery [7]. However, estimation of EBL remains subjective with no consensus on how to estimate it. Furthermore, data on accuracy of EBL are lacking.

Therefore, the aim of this study was to determine whether a simple binary grading of EBL in colon surgery is a reliable and reproducible measure in daily practice.

\section{Methods}

\section{Patients}

This study included all consecutive patients undergoing open and laparoscopic colectomies performed in elective and 
emergency settings between January 2015 and December 2018 in the Visceral Surgery Department at the University Hospital of Lausanne, Switzerland. Colon surgery included right colectomy (including ileocecal resections), extended right colectomy, transverse colectomy, left colectomy, segmental colectomy, sigmoidectomy (including Hartmann procedure) and total colectomy with or without anastomosis. Rectal resections were excluded from this analysis. Patients with other additional intra-abdominal procedures were excluded as well as patients under 18 years old.

\section{EBL measurements}

EBL was prospectively documented by the surgeon and the anaesthesiologist in volume (ml) directly after the intervention. Surgeon EBL was entered in the institutional interactive software (Digistat ${ }^{\circledR}$ ) used for the scheduling and the real-time vision of the operating theatre activity and based on visual estimation. Anaesthesiologist EBL was entered in the patient electronic file and assessed on the basis of the aspirated volume by deducting the lavage volume. The 2 specialists entered the data separately without consulting each other. Binary EBL defined "as usual" vs. "more than usual" was entered by the operating surgeon in the electronic patient file at the end of the operation, and based on subjective feelings regarding intraoperative bleeding, without any other predefined criteria or evaluation scale.

According to several studies [4, 6], clinically relevant EBL cut-off was set at $250 \mathrm{ml}$, which represents a packed red blood cells. Impact of EBL on 30-day postoperative morbidity was analysed.

\section{Data extraction}

Primary extraction was performed from Digistat ${ }^{\circledR}$ using the key words: colectomy, hemicolectomy, sigmoidectomy, Hartmann procedure. Data included type of intervention, indication for surgery, surgeon EBL (ml), operating time (minutes), emergency degree and surgeon expertise (staff surgeon or consultant).

Other data of interest were collected from the institutional electronic patient file. Demographics included age, gender, BMI $\left(\mathrm{kg} / \mathrm{m}^{2}\right)$, malignancy, comorbidities and ASA score. Postoperative data were retrieved from the Enhanced Recovery After Surgery (ERAS) database and included length of stay, intensive care unit (ICU) stay, 30-day postoperative complications and mortality. Overall complications have been graded according to Clavien classification [8]. Severe complications were defined as grade $\geq$ 3 b. Only the highest grade was retained in patients presenting more than one complication.

Differences between pre- and post-operative haemoglobin levels $(\Delta \mathrm{Hb} \mathrm{g} / \mathrm{dl})$ were documented, as well as platelet count and coagulation parameters. Haemoglobin levels were systematically measured on the day before surgery and on postoperative day 1.

\section{Statistics}

Continuous variables were presented as mean with standard deviation (SD) or median with interquartile range (IQR) according to their distribution. Categorical variables were reported as frequencies (\%) and compared with chi-square test. Student's $t$ test or Mann-Whitney test were used for continuous variable comparisons. Statistical correlations between surgeon and anaesthesiologist EBL, as well as between surgeon EBL and $\Delta \mathrm{Hb}$, were measured using Spearman's rank correlation coefficient. All statistical tests were two-sided and a level of 0.05 was used to indicate statistical significance. Statistical analyses were performed with GraphPad Prism 8 (GraphPad Software, Inc., La Jolla, CA, USA).

\section{Ethics}

The study was approved by local Commission on Ethics in Human Research (CER-VD, protocol number 2018-0280) and was conducted in compliance with the current version of the Declaration of Helsinki.

\section{Results}

Three hundred and fourteen patients were assessed, of which $15(4.8 \%)$ were excluded due to an objection to the use of their data for research, and an additional 29 (9.2\%) were excluded due to the absence of documented surgeon and anaesthesiologist EBL. The present study thus included 270 patients.

Demographics, operative indication, malignancy, main comorbidities and laboratory values regarding surgeon EBL ( $<250$ vs. $\geq 250 \mathrm{ml})$ are presented in Table 1 . Surgeon EBL $\geq 250 \mathrm{ml}$ was significantly associated with more emergency procedures.

Surgical details are shown in Table 2. Patients with surgeon $\mathrm{EBL} \geq 250 \mathrm{ml}$ had significantly more open procedures, longer surgical duration and more intraoperative transfusions. A significant drop in haemoglobin level $(\Delta \mathrm{Hb})$ has been observed in patients with surgeon EBL $\geq 250 \mathrm{ml}(-20$ vs $-12.5 \mathrm{~g} / \mathrm{l}, p=0.04)$. Sixteen patients had an intraoperative transfusion $(5.9 \%)$.

Patients with a surgeon EBL $\geq 250 \mathrm{ml}$ had more severe complications $(20 \%$ vs. $8 \%, p=0.02)$. Surgeon and anaesthesiologist mean EBL (ml) levels were lower in "usual" bleeding compared to "more than usual" bleeding $(60 \mathrm{ml}, \mathrm{SD} 77 \mathrm{vs}$ $297 \mathrm{ml}, \mathrm{SD} 149, p<0.001$ and $65.9 \mathrm{ml}$, SD $84 \mathrm{vs} 312.6 \mathrm{ml}$, SD $185, p<0.001$, Fig. 1a, b). Patients with "more than usual" bleeding had significantly more severe complications $(27 \%$ 
Table 1 Baseline demographics, comorbidities and diagnosis: comparison between surgeon $\mathrm{EBL}<250 \mathrm{ml}$ vs $\geq 250 \mathrm{ml}$

\begin{tabular}{|c|c|c|c|c|}
\hline Malignant & $135(50 \%)$ & $118(51 \%)$ & $27(68 \%)$ & \\
\hline Hematochezia as main indication & $10(4 \%)$ & $8(3 \%)$ & $2(5 \%)$ & 0.6 \\
\hline Urgency of surgery & & & & $<0.01$ \\
\hline Elective & $196(73 \%)$ & $174(76 \%)$ & $22(55 \%)$ & \\
\hline Emergency & $74(27 \%)$ & $56(24 \%)$ & $18(45 \%)$ & \\
\hline ASA score & & & & 0.4 \\
\hline 1 & $25(9 \%)$ & $21(9 \%)$ & $4(10 \%)$ & \\
\hline 2 & $134(50 \%)$ & $116(50 \%)$ & $18(45 \%)$ & \\
\hline 3 & $94(35 \%)$ & $79(34 \%)$ & $15(38 \%)$ & \\
\hline 4 & $17(6 \%)$ & $14(7 \%)$ & $3(7 \%)$ & \\
\hline \multicolumn{5}{|l|}{ Preoperative coagulation parameters } \\
\hline $\mathrm{PT}<60 \%$ & $15(6 \%)$ & $13(6 \%)$ & $2(5 \%)$ & 0.8 \\
\hline Thrombocytes $<50$ G/1 & $9(3 \%)$ & $8(3 \%)$ & $1(3 \%)$ & 0.8 \\
\hline
\end{tabular}

Mean $(S D$ standard deviation) or number $(\%)$ as appropriate. Statistical significance $(p<0.05)$ is highlighted in bold

ASA American Association of Anaesthesiologists physical status classification system, PT prothrombine time vs. $8 \%, p=0.001)$, higher mortality ( $11 \%$ vs. $1 \%, p=$ 0.001 ) and longer length of stay (21 vs 12 days, $p=$ 0.004 , Tables 3 and 4).

There was no difference between mean EBL documented by surgeons and anaesthesiologist $(79.5 \mathrm{ml}$, SD 99 vs $84.5 \mathrm{ml}$, SD $118, p=0.57)$. Significant correlation between surgeon and anaesthesiologist EBL was observed ( $\varrho=0.926, p<0.0001$, Fig. $2)$, and surgeon EBL was correlated to $\Delta \mathrm{Hb}(\mathrm{\rho}=-0.273, p=$ 0.01, Fig. 3). A correlation between anaesthesiologist EBL and $\Delta \mathrm{Hb}$ was also observed $(\mathrm{\varrho}=-0.344, p=0.01)$.

\section{Discussion}

No difference between anaesthesiologist and surgeon's EBL was observed in this study, and EBL correlated with $\Delta \mathrm{Hb}$. If blood loss was considered "more than usual" by the surgeon, more severe complications, higher mortality rates and longer length of stay were observed.

There is no gold standard reference for recording intraoperative blood loss. However, EBL is reported in nearly all surgical technical papers as a precious, simple postoperative
Table 2 Surgical details: comparison between surgeon $\mathrm{EBL}<250 \mathrm{ml} \mathrm{vs} \geq 250 \mathrm{ml}$

\begin{tabular}{|c|c|c|c|c|}
\hline & Total $n=270$ & $\begin{array}{l}\mathrm{EBL}<250 \\
\mathrm{ml} n=230\end{array}$ & $\begin{array}{l}\mathrm{EBL} \geq 250 \\
\mathrm{ml} n=40\end{array}$ & $p$ value \\
\hline Approach & & & & $<0.01$ \\
\hline Laparoscopy & $186(69 \%)$ & $171(74 \%)$ & $15(38 \%)$ & \\
\hline Open & $84(31 \%)$ & $59(26 \%)$ & $25(62 \%)$ & \\
\hline Mean surgical time (min; IQR) & $149(71.2)$ & $146(53.9)$ & $201(72.2)$ & $<0.01$ \\
\hline$<2 \mathrm{~h}$ & $27(28 \%)$ & $74(32 \%)$ & $2(5 \%)$ & $<0.01$ \\
\hline$>2 \mathrm{~h}$ & $194(72 \%)$ & $156(68 \%)$ & $38(95 \%)$ & \\
\hline Surgeon & & & & 0.2 \\
\hline Junior staff & $144(53 \%)$ & $119(52 \%)$ & $25(63 \%)$ & \\
\hline Senior staff & $126(47 \%)$ & $111(48 \%)$ & $15(37 \%)$ & \\
\hline Operation during night shift & $32(12 \%)$ & $24(10 \%)$ & $8(20 \%)$ & 0.1 \\
\hline Intra-operative transfusion ( $n$ patients) & $16(6 \%)$ & $6(3 \%)$ & $10(25 \%)$ & $<0.01$ \\
\hline Mean $\Delta \mathrm{Hb}(\mathrm{g} / \mathrm{dl} ; \mathrm{SD})$ & $-1.4(1.6)$ & $-1.3(1.6)$ & $-1.9(1.6)$ & 0.04 \\
\hline "Bleeding as usual" & $240(88 \%)$ & $223(97 \%)$ & $17(43 \%)$ & $<0.01$ \\
\hline "Bleeding more than usual" & $30(12 \%)$ & $7(3 \%)$ & $23(57 \%)$ & \\
\hline
\end{tabular}

Mean (SD standard deviation) or number $(\%)$ as appropriate. Statistical significance $(p<0.05)$ is highlighted in bold. $\Delta \mathrm{Hb}(\mathrm{g} / \mathrm{dl})(=$ post-op $\mathrm{Hb}(\mathrm{g} / \mathrm{dl})$-pre-op $\mathrm{Hb}(\mathrm{g} / \mathrm{dl}))$ 

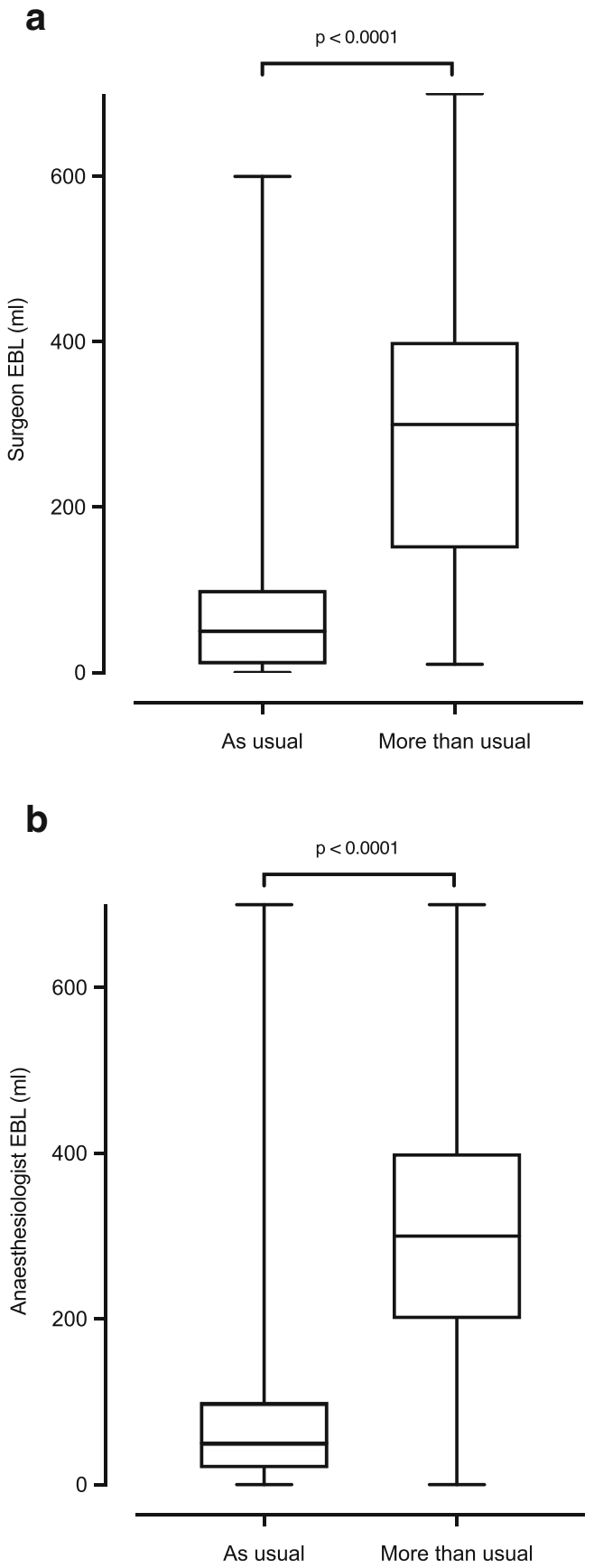

Fig. 1 a, b EBL ( $\mathrm{ml}$ ) comparison between "usual" vs "more than usual" for surgeon (a) and anaesthesiologist (b) data allowing the identification of patients at risk of postoperative complications before they reach the transfusion threshold [9-13]. The association between blood loss and postoperative complications has been reported in colorectal surgery $[2,4,5,14]$, as well as in a range of specialties, including hepatic, gastric and cardiothoracic surgery [15-17]. Furthermore, EBL is used in predictive scores of postoperative adverse events in surgery, such as P-POSSUM [18, 19]. However, estimation of blood loss for a surgical procedure is both poorly reproducible and typically underestimated [20]. Measurement and interpretation of EBL are currently not standardized [20-26]. Despite studies pointing that EBL is not a precise tool, others highlight that accuracy significantly improves with specific training [20-26]. For example Stahl et al. proposed a tool based on the haemoglobin level at 24 and 48 h [24]. Rothermel et al. concluded that visual estimation of operative blood loss was unreliable and inaccurate, and that measurement of the suction liquids added to the weight of gauzes was a better method considered [22]. Ultrasound of the inferior vena cava, contrast enhanced ultrasound, near-infrared spectroscopy, continuous non-invasive intraoperative $\mathrm{Hb}$ monitoring or gravimetric and colorimetric measurements have also been described [27]. In the present study, EBL measured by the anaesthesiologists was based on the suction liquid from which they subtract the flushing liquid. Blood loss estimation made by the surgeon was visual. No differences were displayed between the two observers regarding EBL in volume (ml). Surgeon EBL correlated well with postoperative haemoglobin drop, which may suggest a reliability of the surgeon's estimation.

There is a great heterogeneity of EBL cut-off values and influence on postoperative complications. For example, eight studies reported the influence of blood loss on the rate of anastomotic leaks [4, 14, 28-33]. Two studies [14] concluded that $>300 \mathrm{ml}$ EBL was significantly associated with the risk of anastomotic leak after colectomy while others reported cut-off values $>250 \mathrm{ml}$ [4], > $200 \mathrm{ml}$ [31] to be significantly associated with anastomotic leak. In rectal cancer surgery, even larger volumes were reported $(>1500 \mathrm{ml}$ [30] and $>$ $4500 \mathrm{ml}$ [29]). McGillicudy et al. [5] and Egenvall et al. [34] reported that blood loss $>1000 \mathrm{ml}$ and $>450 \mathrm{ml}$,
Table 3 Post-operative complication and length of stay: comparison of surgeon EBL < $250 \mathrm{ml} \mathrm{vs} \geq 250 \mathrm{ml}$

\begin{tabular}{llll}
\hline & $\mathrm{EBL}<250 \mathrm{ml} n=230$ & $\mathrm{EBL} \geq 250 \mathrm{ml} n=40$ & $p$ value \\
\hline Overall complications & $71(31 \%)$ & $15(38 \%)$ & 0.4 \\
Post-operative bleeding* & $15(7 \%)$ & $4(10 \%)$ & 0.6 \\
Severe complications & $19(8 \%)$ & $8(20 \%)$ & $\mathbf{0 . 0 2}$ \\
30 days mortality & $4(1 \%)$ & $2(5 \%)$ & 0.2 \\
Mean LoS (days) & $13(13)$ & $17(16)$ & 0.09 \\
\hline
\end{tabular}

Mean (SD standard deviation) or number (\%) as appropriate. LoS: length of stay in days. Statistical significance ( $p$ $<0.05$ ) is highlighted in bold. Complications according to Dindo-Clavien classification [1]. Post-operative bleeding: complication defined as grade 2 or more (needed at least one transfusion) according to Dindo-Clavien 
Table 4 Post-operative complication and length of stay: comparison of bleeding as expected vs bleeding more than expected

\begin{tabular}{llll}
\hline & As usual $n=240$ & More than usual $n=30$ & $p$ value \\
\hline Overall complications & $74(31 \%)$ & $12(40 \%)$ & 0.3 \\
Post-operative bleeding* & $15(6 \%)$ & $4(13 \%)$ & 0.2 \\
Severe complications & $19(8 \%)$ & $8(27 \%)$ & $\mathbf{0 . 0 0 1}$ \\
30 days mortality & $3(1 \%)$ & $3(10 \%)$ & $\mathbf{0 . 0 0 1}$ \\
Mean LoS (days) & $12(12)$ & $21(19)$ & $\mathbf{0 . 0 0 4}$ \\
\hline
\end{tabular}

Mean (SD standard deviation) or number (\%) as appropriate. LoS: length of stay in days. Statistical significance ( $p$ $<0.05$ ) is highlighted in bold. Complications according to Dindo-Clavien classification [1]. Post-operative bleeding: complication defined as grade 2 or more (needed at least one transfusion) according to Dindo-Clavien respectively, was significantly associated with mortality. Volume of EBL in $\mathrm{ml}$ and their impact on outcome vary greatly.

In the present study, EBL greater or equal to $250 \mathrm{ml}$ correlated to post-operative complications but did not correlate to post-operative mortality. A simple binary EBL grading correlated with both 30-day postoperative complications and mortality. Looking at the correlation between objective blood loss and subjective binary estimation, it is obvious that EBL < $250 \mathrm{ml}$ seems to be "usual" for most surgeons. Interestingly, EBL of $>250 \mathrm{ml}$ seems to trigger the assessment "more than usual" in only about half of the cases in the present study. Therefore, the trigger to assess blood loss as "more than usual" seems to be higher than $250 \mathrm{ml}$ for most surgeons. This could explain the higher correlation between morbidity and mortality of the binary EBL in comparison with measured EBL. However, complex and non-validated measurement methods that have been described for EBL could be avoided and replaced by this completely subjective and binary measure,

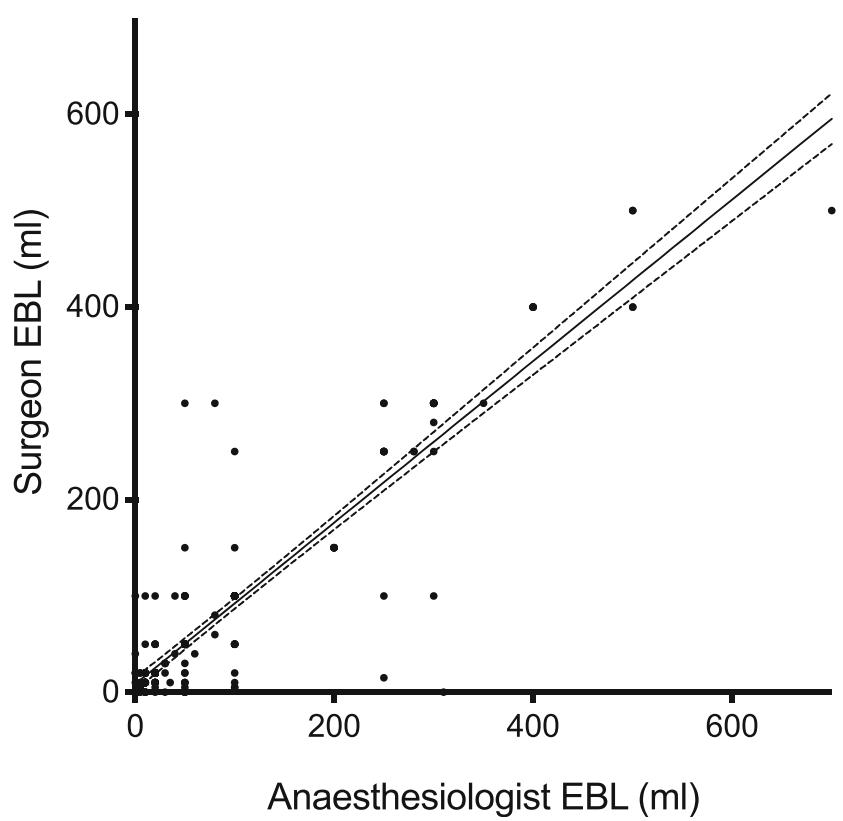

Fig. 2 Correlation between surgeon EBL (ml) vs anaesthesiologist EBL (ml). Caption: $\mathrm{Q}=0.9259, p<0.0001$ which is equivalent to estimation in volume but much easier and faster to apply in surgeon's daily practice. This would allow to predict postoperative outcomes and thus adapt management with the aim of improving patient outcome. It could also be considered to indicate the need for early postoperative transfusions. However, this needs to be demonstrated in welldesigned large-scale study.

Several limitations of the present study need to be addressed. First, the relatively small sample size and the retrospective analyses could both affect the quality of the data. However, all values were collected prospectively, as well as the binary grading of EBL. Furthermore, it cannot be excluded that surgeons and anaesthesiologist agreed on the volume $(\mathrm{ml})$ at the end of the operation even if they documented it separately. There was, however, no systematic communication between the surgeon and the anaesthesiologists on EBL and both could have over- or under-estimate intraoperative blood

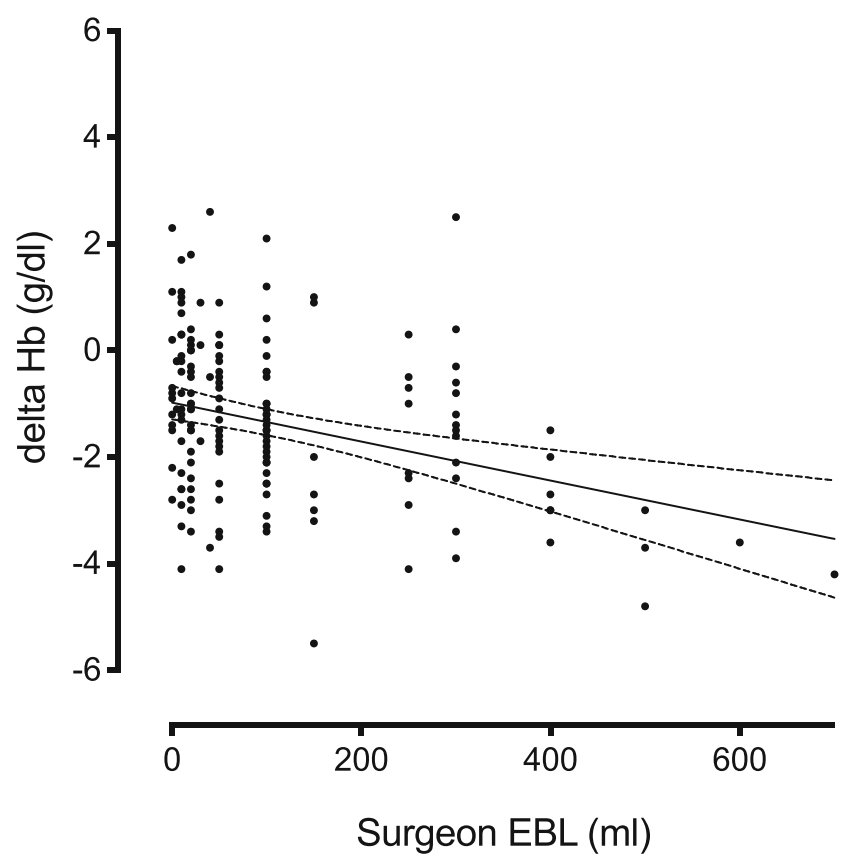

Fig. 3 Correlation between surgeon EBL $(\mathrm{ml})$ and difference between pre- and post-operative $\mathrm{Hb}$ values $(\mathrm{g} / \mathrm{dl})$ (delta $\mathrm{Hb}$ ). Caption: $\mathrm{\rho}=-$ $0.2730, p=0.01$ 
loss. Indeed, only one anaesthesiologist and one surgeon completed the form, and no inter-rater reliability (Cohen's kappa coefficient) was done. Another point to consider is the fact that the subjective evaluation could represent the postoperative state of mind of the surgeon, and instinctively, one would tend to overestimate the bleeding if the surgery is complex, thus inserting potential bias. Otherwise, changes in $\mathrm{Hb}$ levels are dependent on the hydration of the patient and the volume of fluids administered during surgery. In this study, this aspect was not considered which could have induced bias. As previously described, clinically relevant EBL cut-off was set at

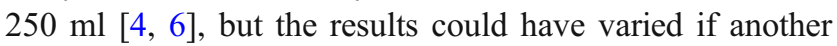
cut-off had been chosen. In addition, after long and stressful procedures, surgeons may tend to overestimate the blood loss ("more than usual"), and due to the increased fluid volumes, the resulting $\Delta \mathrm{Hb}$ may support the value of the binary EBL. Depending on the patient (comorbidities, coagulation disorders, preoperative anaemia) or the surgeon, this subjective estimation may vary. Further investigations are required to see if it is reproducible and generalizable on a large scale.

\section{Conclusion}

In conclusion, there was no difference between anaesthesiologist and surgeon's EBL. If blood loss was considered "more than usual" by the surgeon, more severe complications, higher mortality rates and longer length of stay were observed. Thus, EBL in volume did not appear superior to simple binary subjective estimation from the surgeon, which was reliable in predicting postoperative outcomes in colon surgery.

Author contribution Hugo Teixeira Farinha, David Martin, Audrey Ramó, Martin Hübner, Nicolas Demartines and Dieter Hahnloser meet all the criteria for the definition of authorship and contributed substantially to the manuscript. Dieter Hahnloser is the correspondent author.

Funding Open Access funding provided by Université de Lausanne.

\section{Declarations}

Ethics approval The study was approved by local Commission on Ethics in Human Research (CER-VD, protocol number 2018-0280) and was conducted in compliance with the current version of the Declaration of Helsinki.

Conflict of interest The authors declare no competing interests.

Open Access This article is licensed under a Creative Commons Attribution 4.0 International License, which permits use, sharing, adaptation, distribution and reproduction in any medium or format, as long as you give appropriate credit to the original author(s) and the source, provide a link to the Creative Commons licence, and indicate if changes were made. The images or other third party material in this article are included in the article's Creative Commons licence, unless indicated otherwise in a credit line to the material. If material is not included in the article's Creative Commons licence and your intended use is not permitted by statutory regulation or exceeds the permitted use, you will need to obtain permission directly from the copyright holder. To view a copy of this licence, visit http://creativecommons.org/licenses/by/4.0/.

\section{References}

1. Alves A, Panis Y, Mathieu P, Mantion G, Kwiatkowski F, Slim K, Association Francaise de C (2005) Postoperative mortality and morbidity in French patients undergoing colorectal surgery: results of a prospective multicenter study. Arch Surg 140(3):278-283, discussion 284. https://doi.org/10.1001/archsurg.140.3.278

2. Artinyan A, Nunoo-Mensah JW, Balasubramaniam S, Gauderman J, Essani R, Gonzalez-Ruiz C, Kaiser AM, Beart RW Jr (2008) Prolonged postoperative ileus-definition, risk factors, and predictors after surgery. World J Surg 32(7):1495-1500. https://doi.org/ 10.1007/s00268-008-9491-2

3. Alhashemi M, Fiore JF Jr, Safa N, Al Mahroos M, Mata J, Pecorelli N, Baldini G, Dendukuri N, Stein BL, Liberman AS, Charlebois P, Carli F, Feldman LS (2019) Incidence and predictors of prolonged postoperative ileus after colorectal surgery in the context of an enhanced recovery pathway. Surg Endosc 33(7):2313-2322. https://doi.org/10.1007/s00464-018-6514-4

4. Post IL, Verheijen PM, Pronk A, Siccama I, Houweling PL (2012) Intraoperative blood pressure changes as a risk factor for anastomotic leakage in colorectal surgery. Int J Color Dis 27(6):765-772. https://doi.org/10.1007/s00384-011-1381-7

5. McGillicuddy EA, Schuster KM, Davis KA, Longo WE (2009) Factors predicting morbidity and mortality in emergency colorectal procedures in elderly patients. Arch Surg 144(12):1157-1162. https://doi.org/10.1001/archsurg.2009.203

6. Morner ME, Gunnarsson U, Jestin P, Svanfeldt M (2012) The importance of blood loss during colon cancer surgery for long-term survival: an epidemiological study based on a population based register. Ann Surg 255(6):1126-1128. https://doi.org/10.1097/ SLA.0b013e3182512df0

7. Kirchhoff P, Clavien PA, Hahnloser D (2010) Complications in colorectal surgery: risk factors and preventive strategies. Patient Saf Surg 4(1):5. https://doi.org/10.1186/1754-9493-4-5

8. Dindo D, Demartines N, Clavien PA (2004) Classification of surgical complications: a new proposal with evaluation in a cohort of 6336 patients and results of a survey. Ann Surg 240(2):205-213

9. Jarnagin WR, Gonen M, Fong Y, DeMatteo RP, Ben-Porat L, Little S, Corvera C, Weber S, Blumgart LH (2002) Improvement in perioperative outcome after hepatic resection: analysis of 1,803 consecutive cases over the past decade. Ann Surg 236(4):397-406; discussion 406-397. https://doi.org/10.1097/01.SLA.0000029003. 66466.B3

10. Katz SC, Shia J, Liau KH, Gonen M, Ruo L, Jarnagin WR, Fong Y, D'Angelica MI, Blumgart LH, Dematteo RP (2009) Operative blood loss independently predicts recurrence and survival after resection of hepatocellular carcinoma. Ann Surg 249(4):617-623. https://doi.org/10.1097/SLA.0b013e31819ed22f

11. Imamura H, Seyama Y, Kokudo N, Maema A, Sugawara Y, Sano K, Takayama T, Makuuchi M (2003) One thousand fifty-six hepatectomies without mortality in 8 years. Arch Surg 138(11):11981206; discussion 1206. https://doi.org/10.1001/archsurg.138.11. 1198

12. Shimada M, Matsumata T, Akazawa K, Kamakura T, Itasaka H, Sugimachi K, Nose Y (1994) Estimation of risk of major 
complications after hepatic resection. Am J Surg 167(4):399-403. https://doi.org/10.1016/0002-9610(94)90124-4

13. Yoshimura Y, Kubo S, Shirata K, Hirohashi K, Tanaka H, Shuto T, Takemura S, Kinoshita H (2004) Risk factors for postoperative delirium after liver resection for hepatocellular carcinoma. World J Surg 28(10):982-986. https://doi.org/10.1007/s00268-004-73441

14. Leichtle SW, Mouawad NJ, Welch KB, Lampman RM, Cleary RK (2012) Risk factors for anastomotic leakage after colectomy. Dis Colon Rectum 55(5):569-575. https://doi.org/10.1097/DCR. 0b013e3182423c0d

15. Karkouti K, Wijeysundera DN, Yau TM, Beattie WS, Abdelnaem E, McCluskey SA, Ghannam M, Yeo E, Djaiani G, Karski J (2004) The independent association of massive blood loss with mortality in cardiac surgery. Transfusion 44(10):1453-1462. https://doi.org/10. 1111/j.1537-2995.2004.04144.x

16. Nakamura H, Saji H, Kurimoto N, Shinmyo T, Tagaya R (2015) Impact of intraoperative blood loss on long-term survival after lung cancer resection. Ann Thorac Cardiovasc Surg 21(1):18-23. https:// doi.org/10.5761/atcs.oa.13-00312

17. Stenberg E, Szabo E, Naslund I, Ottosson J (2017) Bleeding during laparoscopic gastric bypass surgery as a risk factor for less favorable outcome. A cohort study from the Scandinavian Obesity Surgery Registry. Surg Obes Relat Dis 13(10):1735-1740. https:// doi.org/10.1016/j.soard.2017.05.028

18. Horzic M, Kopljar M, Cupurdija K, Bielen DV, Vergles D, Lackovic Z (2007) Comparison of P-POSSUM and Cr-POSSUM scores in patients undergoing colorectal cancer resection. Arch Surg 142(11):1043-1048. https://doi.org/10.1001/archsurg.142. 11.1043

19. Al-Homoud S, Purkayastha S, Aziz O, Smith JJ, Thompson MD, Darzi AW, Stamatakis JD, Tekkis PP (2004) Evaluating operative risk in colorectal cancer surgery: ASA and POSSUM-based predictive models. Surg Oncol 13(2-3):83-92. https://doi.org/10.1016/j. suronc.2004.08.006

20. Brecher ME, Monk T, Goodnough LT (1997) A standardized method for calculating blood loss. Transfusion 37(10):1070-1074. https://doi.org/10.1046/j.1537-2995.1997.371098016448.x

21. Meiser A, Casagranda O, Skipka G, Laubenthal H (2001) Quantification of blood loss. How precise is visual estimation and what does its accuracy depend on? Anaesthesist 50(1):13-20. https://doi.org/10.1007/s001010050957

22. Rothermel LD, Lipman JM (2016) Estimation of blood loss is inaccurate and unreliable. Surgery 160(4):946-953. https://doi.org/ 10.1016/j.surg.2016.06.006

23. Yeung CY, Yim WW, Chan SY, Lo RSL, Leung LY, Hung KKC, Graham CA (2017) Improvement of blood loss volume estimation by paramedics using a pictorial nomogram: a developmental study. Injury 48(12):2693-2698. https://doi.org/10.1016/j.injury.2017.10. 045

24. Stahl DL, Groeben H, Kroepfl D, Gautam S, Eikermann M (2012) Development and validation of a novel tool to estimate peri- operative blood loss. Anaesthesia 67(5):479-486. https://doi.org/ 10.1111/j.1365-2044.2011.06916.x

25. Dildy GA 3rd, Paine AR, George NC, Velasco C (2004) Estimating blood loss: can teaching significantly improve visual estimation? Obstet Gynecol 104(3):601-606. https://doi.org/10.1097/01.AOG. 0000137873.07820 .34

26. Merlin MA, Alter SM, Raffel B, Pryor PW 2nd (2009) External blood loss estimation using the MAR Method. Am J Emerg Med 27(9):1085-1090. https://doi.org/10.1016/j.ajem.2008.07.039

27. Gerdessen L, Meybohm P, Choorapoikayil S, Herrmann E, Taeuber I, Neef V, Raimann FJ, Zacharowski K, Piekarski F (2020) Comparison of common perioperative blood loss estimation techniques: a systematic review and meta-analysis. J Clin Monit Comput 35:245-258. https://doi.org/10.1007/s10877-020-00579-8

28. Okamura R, Hida K, Hasegawa S, Sakai Y, Hamada M, Yasui M, Hinoi T, Watanabe M, Japan Society of Laparoscopic Colorectal S (2016) Impact of intraoperative blood loss on morbidity and survival after radical surgery for colorectal cancer patients aged 80 years or older. Int J Color Dis 31(2):327-334. https://doi.org/10. 1007/s00384-015-2405-5

29. Vermeer TA, Orsini RG, Daams F, Nieuwenhuijzen GA, Rutten HJ (2014) Anastomotic leakage and presacral abscess formation after locally advanced rectal cancer surgery: Incidence, risk factors and treatment. Eur J Surg Oncol 40(11):1502-1509. https://doi.org/10. 1016/j.ejso.2014.03.019

30. Warschkow R, Steffen T, Thierbach J, Bruckner T, Lange J, Tarantino I (2011) Risk factors for anastomotic leakage after rectal cancer resection and reconstruction with colorectostomy. A retrospective study with bootstrap analysis. Ann Surg Oncol 18(10): 2772-2782. https://doi.org/10.1245/s10434-011-1696-1

31. Telem DA, Chin EH, Nguyen SQ, Divino CM (2010) Risk factors for anastomotic leak following colorectal surgery: a case-control study. Arch Surg 145(4):371-376; discussion 376. https://doi.org/ 10.1001/archsurg. 2010.40

32. Wang HM, Hsu H, Chen SS, Liou TY (1989) Postoperative leakage of rectal cancer after EEA stapled anastomoses-analysis of 196 cases. Gaoxiong Yi Xue Ke Xue Za Zhi 5(7):398-403

33. Rutkowski A, Olesinski T, Zajac L, Bednarczyk M, Szpakowski M (2017) The risk of anastomotic leakage after anterior resection: retrospective analysis of 501 rectal cancer patients operated without protective stoma. Minerva Chir 72(6):491-498. https://doi.org/10. 23736/S0026-4733.17.07411-9

34. Egenvall M, Morner M, Pahlman L, Gunnarsson U (2014) Degree of blood loss during surgery for rectal cancer: a population-based epidemiologic study of surgical complications and survival. Color Dis 16(9):696-702. https://doi.org/10.1111/codi.12630

Publisher's note Springer Nature remains neutral with regard to jurisdictional claims in published maps and institutional affiliations. 